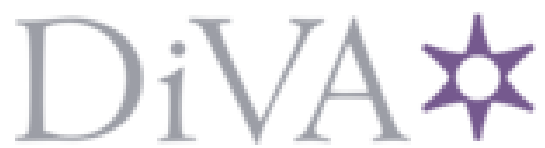

http://www.diva-portal.org

This is the published version of a paper presented at EURODYN 2020, XI International Conference on Structural Dynamics, 23-26 November 2020, Athens, Greece.

Citation for the original published paper:

Landel, P., Linderholt, A. (2020)

Validation of a structural model of a large timber truss with slotted-in steel plates and dowels

In: M. Papadrakakis National Technical University of Athens, Greece M. Fragiadakis National Technical University of Athens, Greece C. Papadimitriou University of Thessaly, Greece (ed.), EURODYN 2020, Proceedings of the XI International Conference on Structural Dynamics (pp. 4349-4357). Institute of Structural Analysis and Antiseismic Research School of Civil Engineering National Technical University of Athens (NTUA)

N.B. When citing this work, cite the original published paper.

Permanent link to this version:

http://urn.kb.se/resolve?urn=urn:nbn:se:lnu:diva-99514 


\title{
VALIDATION OF A STRUCTURAL MODEL OF A LARGE TIMBER TRUSS WITH SLOTTED-IN STEEL PLATES AND DOWELS
}

\author{
Pierre Landel $^{1,2}$ and Andreas Linderholt ${ }^{2}$ \\ ${ }^{1}$ Research Institutes of Sweden \\ e-mail: pierre.landel@ri.se \\ ${ }^{2}$ Linnaeus University Sweden \\ e-mail: \{pierre.landel, andreas.linderholt\}@1nu.se
}

Keywords: Glued-Laminated-Timber (Glulam) truss, slotted-in steel plates and dowels connection, experimental and numerical modal analysis, stiffness, damping, induced vibrations in timber structure.

\begin{abstract}
The dynamic response to time varying loads, e.g. wind loads or earthquakes, is in many cases decisive when designing a tall timber building. The structural parameters governing the dynamic behaviour are the mass, the damping and the stiffness. The last two parameters are not well-known at serviceability levels for timber structures in general and for timber connections specifically. Results from forced vibration tests on single components and on a full-scale truss for an eight-storey residential building have been analyzed. In parallel, a detailed Finite Element (FE) model of a large Glulam truss with slotted-in steel plates and dowels connections has been developed and simulations have been made. The damping caused by the structural components, the embedment of fasteners and friction of mating surfaces of components in the selected connection types is quantified experimentally. The materials' stiffness values in the model were evaluated. The results from this study bring knowledge on the structural dynamic properties of large timber structures with mechanical connections and will facilitate the performance prediction of new tall timber buildings for better comfort at higher levels in environmentally friendly expansions of our cities.
\end{abstract}




\section{INTRODUCTION}

Tall timber buildings are becoming more common due to their environmental benefits and low weights. Large engineered wood products such as Glulam members or Cross-LaminatedTimber plates are often used. For instance, the largest column of the 18-storey Mjøstårnet in Norway, is made of glued spruce lumbers and has a cross sectional area equal to $625 \mathrm{x} 1485$ $\mathrm{mm}^{2}$. To assemble the structural elements, slotted-in steel plates and dowels are used [1]. This connection technique has traditionally been used in long-span bridges and roof structures. Moreover, the density and the modulus of elasticity of the wood material are well known; they are lower than the corresponding values for steel and concrete. When the height of timber buildings rises in cities around the world, new types of challenges appear for structural designers. One of them is wind-induced vibrations which appears to be annoying for the occupants at lower heights for buildings made of timber than for traditional high-rise buildings [2]. Mass, stiffness and damping matrices (denoted $\mathrm{M}, \mathrm{K}$ and $\mathrm{C}$ ) need to be fairly well known to accurately predict responses of structures subjected to time varying excitations. For tall timber buildings, it is relevant to analyze the accuracy of the mass and stiffness matrices used by structural designers in FE-analysis for serviceability load levels. Unfortunately, some dynamical properties of large timber structures are not well known [2]. The damping is the least known dynamical property and recently started research projects aim to close the knowledge gap through ambient vibration tests [3, 4, 5] and forced vibration tests of tall timber buildings [6].

The load distribution in timber structures depends on the stiffness of the structural elements and the stiffness of the connections. Glulam structures are usually modeled as beam elements with well-known stiffness but the load distribution in connections with multiple fasteners is uncertain. The joints are often modelled either with constrains in displacement and rotation, i.e. clamped, or only with constrains in displacement, i.e. pinned [1]. Most connections in Glulam structures consist of many steel dowels and several slotted-in steel plates in parallel. However, most of the experimental and numerical studies have been performed on single dowel connections. Building design codes for timber structures propose simple parameters to evaluate the slip of single connections, e.g. [7] and [8] but better slip models for connections with multiple fasteners and several shear planes are needed [9]. Wood is a complex material to model: high orthotropy, inhomogeneities at different scales and large variability, and this must be considered when predicting the embedment between timber and steel [10]. Phenomenological models for embedment have recently been developed based on the beam on foundation approach [11], with elastic and plastic foundation modulus [12]. Such material models are suitable for beam element models to predict deformations and load capacity. Constitutive models with non-linear material stiffness and embedment stiffness with criteria for yielding and softening $[13,14,15]$ have also been developed recently and they are applicable to solid FE-models mainly to predict load capacity but not focusing on the deformations at serviceability levels.

Damping in timber structures has mainly been studied experimentally through cyclic tests, representing seismic load histories, on single components or large structures [16], but not much through vibrational tests to assess the damping at serviceability levels [17]. Standard values of the critical viscous damping ratio are set to $1 \%$ and $1.5 \%$ for timber bridges without respectively with mechanical connections when designed for pedestrian induced vibrations [18]. 


\section{FORCED VIBRATION TESTS ON A LARGE TIMBER TRUSS}

\subsection{The Glulam truss}

A truss made of Glulam members assembled with slotted-in steel plates and dowels connections has been vibrational tested in the factory where it was manufactured, in Töreboda, Sweden. It has 14 Glulam members of quality GL30c according to [19], an overall height of $18.5 \mathrm{~m}$ and a width of $4.3 \mathrm{~m}$. It is now part of the lateral stabilizing timber structure of a six-storey residential building and it stands up on a concrete foundation to prevent the building from collapse in case of strong winds. The short elements, diagonals and beams have a rectangular cross-section of $215 \times 360 \mathrm{~mm}$. The first column has a rectangular cross-section of $215 \times 540 \mathrm{~mm}$. The second column is composed of a similar cross-section glued with $90 \times 215$ members on each side to form a T-shaped cross-section. Holes, cutting and details for the Glulam members were made with a CNC-machine. The steel plates and the dowels are made of S355JO steel quality. The plates are $8 \mathrm{~mm}$ thick and weight between 8 and $37 \mathrm{~kg}$. The dowels are $12 \mathrm{~mm}$ in diameter and have a length of $210 \mathrm{~mm}$. Each connection has two steel plates and 8 to 45 dowels hammered in each timber member. In total there are 650 dowels and 28 steel plates in the truss. Heavy steel feet with welded $8 \mathrm{~mm}$ plates, weighting 88 and $106 \mathrm{~kg}$, are mounted with dowels at the end of both columns. The overall weight of the Glulam truss including the steel elements is $4280 \mathrm{~kg}$ and the densities of the timber members have been measured and the mean density was evaluated to $426.8 \mathrm{~kg} / \mathrm{m}^{3}$.

\subsection{The vibration test}

When the truss was assembled, forced vibrations tests (FVT) were made at the factory. With overhead cranes, the truss was lifted from the ground with lift straps placed close to the center of gravity of the truss, see figure 1. Excitations were made in different directions on and close to the steel foot of the lower column (bottom end) with a short-sledge impulse hammer. During the tests, fourteen tri-axial piezo electrical accelerometers at the center of each truss connection and twelve single axial accelerometers on the middle of the short Glulam elements were used. The accelerometers, with a sensitivity of $100 \mathrm{mV} / \mathrm{g}( \pm 10 \%)$, were glued on one side of the Glulam members. The data were recorded with an LMS data acquisition system with 56 input channels that measured 50 accelerations in the $\mathrm{X}$ - Y- or Z-directions, see figure 1, and the excitation force from the impulse hammer.

Further information on the Glulam truss properties and details of the vibration test performed are available in paper [20].

\section{A NUMERICAL MODEL OF THE LARGE TIMBER TRUSS}

\subsection{The 3D FE-model with solid elements}

The Glulam truss has been modeled, as an FE-model, to numerically evaluate the structural dynamic properties and compare them with the experimental results. The model was developed using the pre- and post-processor MSC Simxpert and analyzed with the FE-solver MSC Nastran. The model consists of 1726778 eight-noded solid elements (CHEXA) and 523961 six-noded solid elements (CPENTA) with a total of 2715641 nodes. Different element sizes have been used with densified meshes around details such as the holes for the dowels in the timber members and the steel parts and coarser meshes in areas without complexity, see figure 2 . To ensure continuity between solid elements from the same part but with non-congruent meshes, contact constraints paired and permanently glued slaves contact bodies to masters contact bod- 


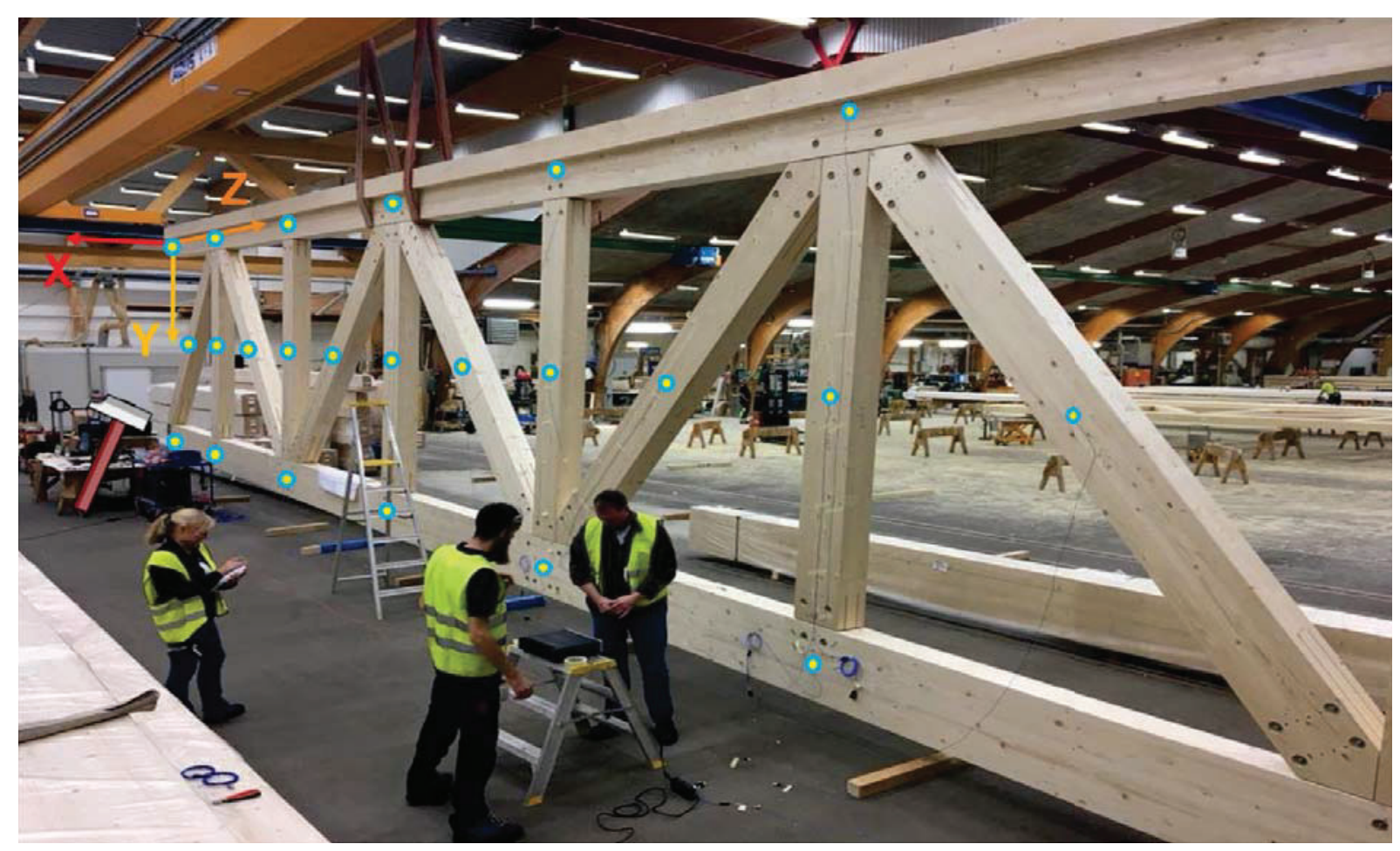

Figure 1: The Glulam truss during a forced vibration test.

\begin{tabular}{|c|c|c|c|c|}
\hline $\begin{array}{l}\text { Modulus of elas- } \\
\text { ticity parallel to } \\
\text { the fiber direction }\end{array}$ & $\begin{array}{l}\text { Modulus of elas- } \\
\text { ticity perpendicu- } \\
\text { lar to the fiber }\end{array}$ & $\begin{array}{l}\text { Shear modulus } \\
\text { in the } 0,90 \text {-plane }\end{array}$ & $\begin{array}{l}\text { Shear mod- } \\
\text { ulus in the } \\
90,90 \text {-plane }\end{array}$ & $\begin{array}{l}\text { Poisson's } \\
\text { ratios }\end{array}$ \\
\hline $\begin{array}{l}\mathrm{E}_{0} \in[10.5,11.8] \\
\text { in } \mathrm{GPa}\end{array}$ & $\mathrm{E}_{90}=300 \mathrm{MPa}$ & $\mathrm{G}_{0,90}=650 \mathrm{MPa}$ & $\mathrm{G}_{90,90}=65 \mathrm{MPa}$ & $\begin{array}{l}\nu_{0,90}=0.5 \\
\nu_{90,90}=0.2\end{array}$ \\
\hline acc. to $[20]$ & acc. to [19] & acc. to [19] & acc. to [19] & acc. to [21] \\
\hline
\end{tabular}

Table 1: The material properties used in the FE-models of the Glulam members.

ies with non-congruent meshes. Permanent glue contacts constrained parts of different material together, i.e. timber member to dowel and dowel to steel plates. The MSC Nastran node-tosegment contact method has been used and it created multi-point constraint equations among the nodes from a slave body which met the surface of a master body. Then, the augmented Lagrange multiplier method was used to embed constraints into the modal analysis.

Steel parts were modeled using an isotropic material model with a Young's modulus of 210 $\mathrm{GPa}$, a Poisson's ratio of 0.3 and a density of $7850 \mathrm{~kg} / \mathrm{m}^{3}$. The Glulam members were modeled using an orthotropic material model with the six stiffness parameters presented in Table 1.

Two spring elements representing the hoisting loops were attached to the ground and to several points of the upper timber column with an interpolation constraint element (RBE3). The RBE3 elements defined the motion at a reference grid point as the weighted average of the motions at a set of other grid points. The axial stiffness of the springs was calibrated to match the natural frequency of the global bouncing mode in the Y-direction from the experimental results. 

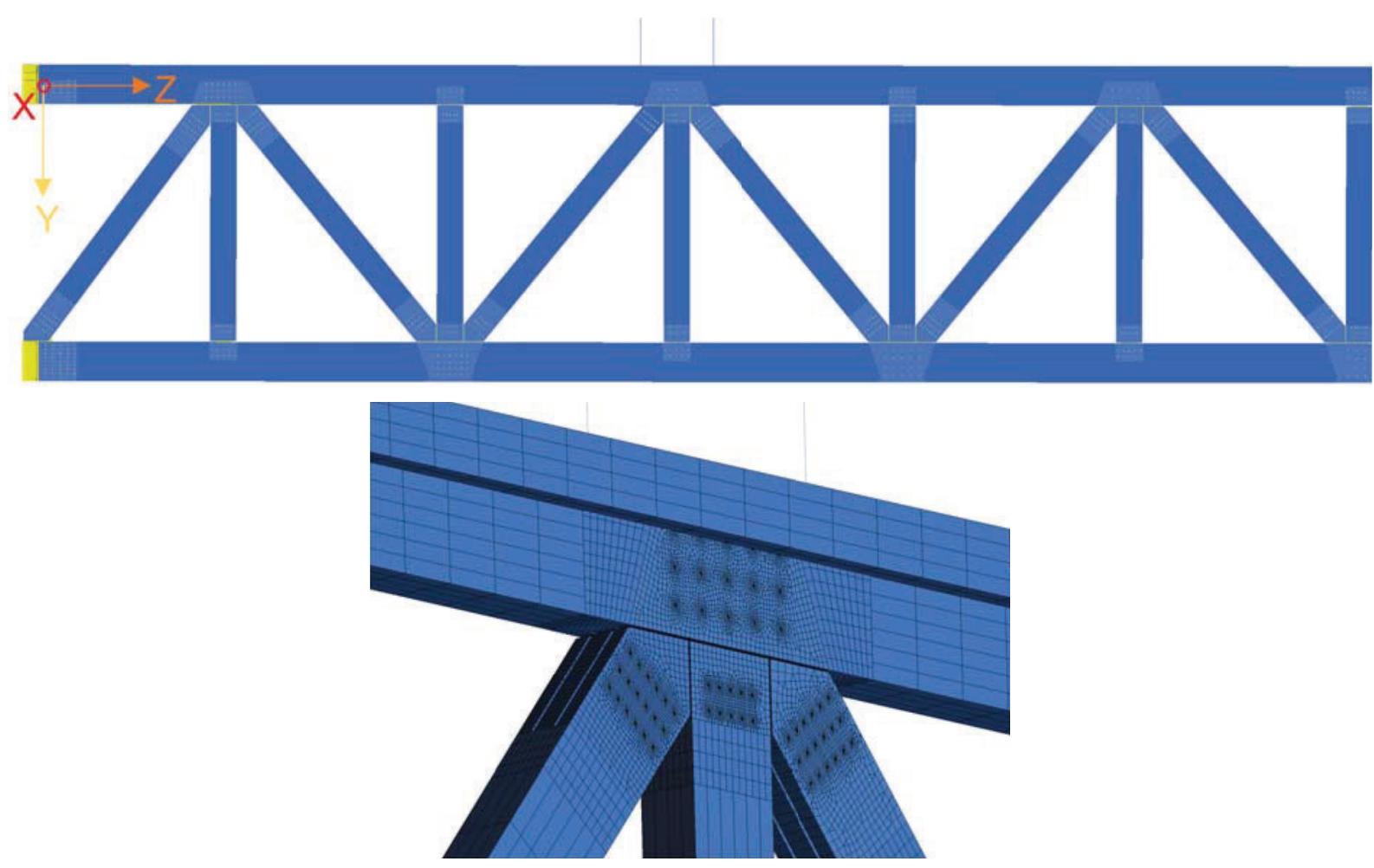

Figure 2: a) the FE-model representing the truss and b) the meshing details of the top-middle connection.

\subsection{The numerical analysis}

In a structural dynamic system without damping, the vectors of displacement, $u$, and acceleration, $\ddot{u}$, are related to the mass matrix $[M]$, the stiffness matrix $[K]$ and the excitation force vector, $p$, according to the equation of motion:

$$
[M] \ddot{u}+[K] u=p
$$

The eigenfrequencies and eigenmode shapes of the model were extracted using the normal mode analysis in MSC Nastran implementing the block shifted Lanczos eigenvalue extraction method. The numerical mode shapes with very low displacement out of the plane of the truss, which is the structurally operational plane, and with eigenfrequencies between 5 and $130 \mathrm{~Hz}$ were investigated.

\section{COMPARISON AND DISCUSSION}

During the FVT, five eigenmodes corresponding to motion in the plane of the truss and with eigenfrequencies between $5 \mathrm{~Hz}$ and $100 \mathrm{~Hz}$ were identified and their corresponding mode shapes and damping values were extracted. From the numerical analysis, 23 in-plane eigenmodes were calculated. Modal Assurance Criterion (MAC) values comparing the experimental modes shapes $\Phi_{r}^{X}$, stemming from modal testing, to the analytical mode shapes $\Phi_{s}^{A}$, stemming from the FE-analysis, are calculated according to equation 2 and are presented in the matrix in figure 3.

$$
M A C_{r, s}=\frac{\left(\Phi_{r}^{X^{T}} \Phi_{s}^{A}\right)^{2}}{\Phi_{r}^{X^{T}} \Phi_{r}^{X} \Phi_{s}^{A^{T}} \Phi_{s}^{A}}
$$




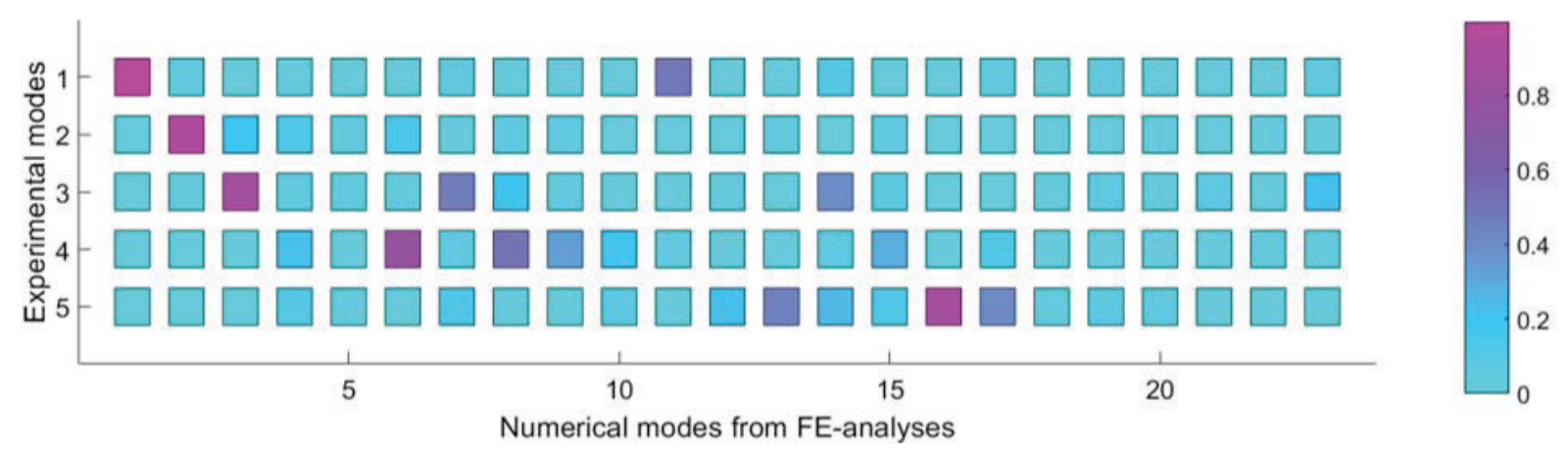

Figure 3: A representation of the MAC matrix comparing experimental mode shapes to numerical mode shapes.

According to the MAC values, five numerical modes (mode 1, 2, 3, 6 and 16) have high consistency with the five experimental modes ; their MAC values are between 0.88 and 0.99 . Table 2 presents graphical representations of the mode shapes, the eigenfrequencies, the experimental damping and the MAC values of the paired eigenmodes. The numerical eigenmode 2 corresponds to a local motion of the end of the pillar and matches in both eigenfrequency and shape the paired experimental eigenmode 2. The numerical eigenmodes 3,6 and 16 are stiffer and have eigenfrequencies $10 \%$ higher than their experimental counterparts. These modes are global bending vibration modes and are of interest when investigating structural timber trusses aimed for stabilization against lateral forces e.g. wind loads. The total mass of the glulam and the stiffness of the single elements are correct at a global scale. At a smaller scale, slightly lower than the diameter of the dowels, timber presents large variability in the density and in the orthotropic stiffnesses [22]. At this lower scale, the embedment stiffness between timber and dowels is sensitive to the local variations of the modulus of elasticity and the shear modulus. Higher frequencies in the numerical models can signify that this embedment stiffness in the FE-model is overestimated. Linear material model for timber with standard elastic modulus stemming from clear wood testing might not be suitable. Bi-linear material models with a yield criterion for timber friction and gaps between timber and dowels should be considered in FE-models made of solid element to predict the dynamic properties of timber structures. The damping ratios (relative to the critical viscous damping) from the test data of the experimental modes 2, 3, 4 and 5 vary between $0.6 \%$ and $1.0 \%$. They are lower than the damping ratios of timber floors tested in lab [17] and the standard values for timber bridges [18].

Experimental results Numerical results

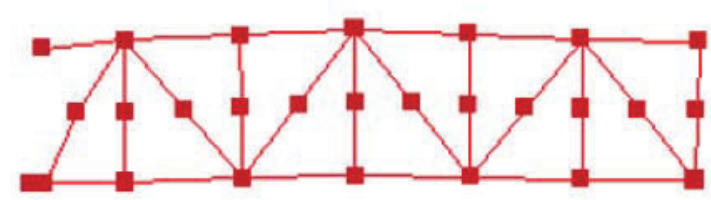

Exp. 1: $8.97 \mathrm{~Hz}$ and $\zeta_{1}=1.7 \%$

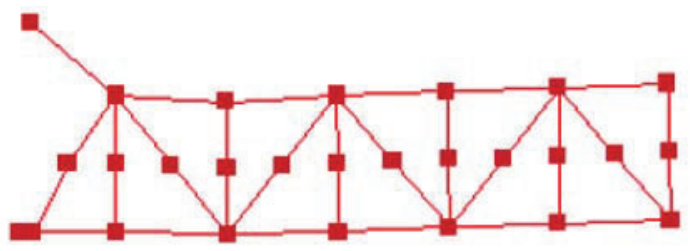

Exp. 2: $25.25 \mathrm{~Hz}$ and $\zeta_{2}=0.9 \%$

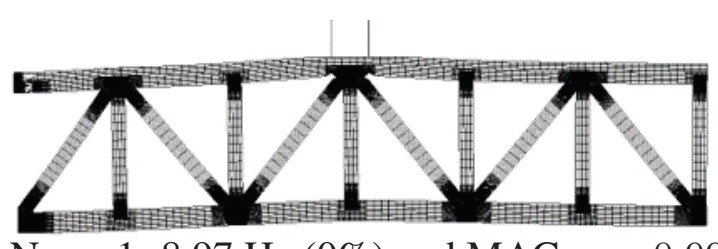

Num. 1: $8.97 \mathrm{~Hz}(0 \%)$ and $\mathrm{MAC}_{1,1}=0.99$

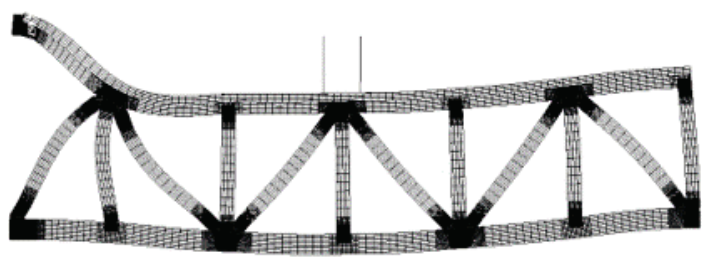

Num. 2: $26.9 \mathrm{~Hz}(+6 \%)$ and $\mathrm{MAC}_{2,2}=0.99$ 


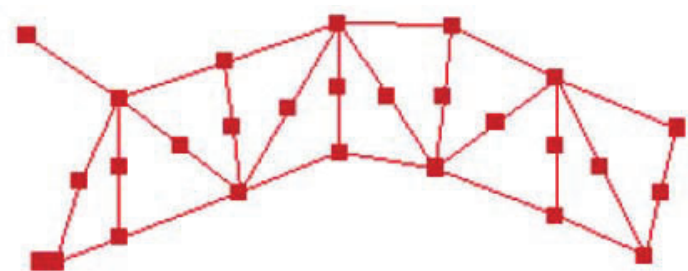

Exp. 3: $42.65 \mathrm{~Hz}$ and $\zeta_{3}=1.0 \%$

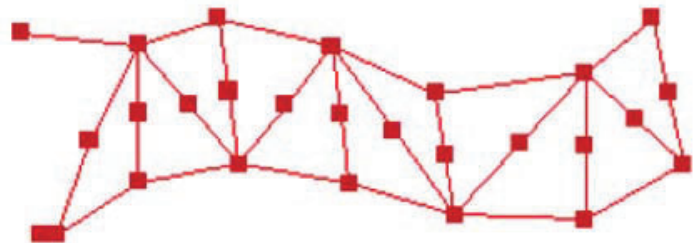

Exp. 4: $61.57 \mathrm{~Hz}$ and $\zeta_{4}=0.6 \%$

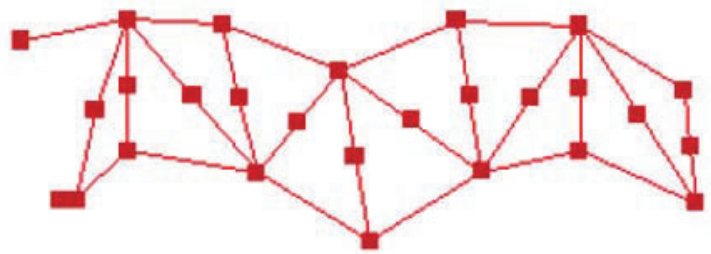

Exp. 5: $92.78 \mathrm{~Hz}$ and $\zeta_{5}=0.7 \%$

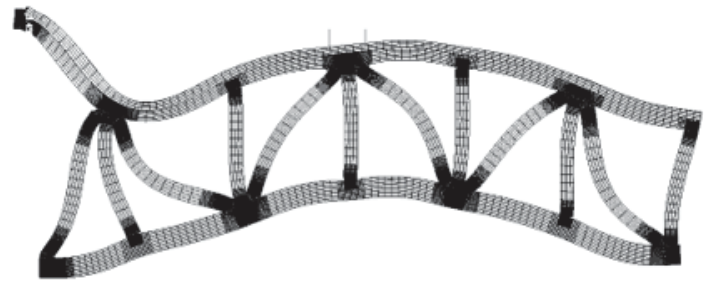

Num. 3: $47.5 \mathrm{~Hz}(+11 \%)$ and $\mathrm{MAC}_{3,3}=0.97$

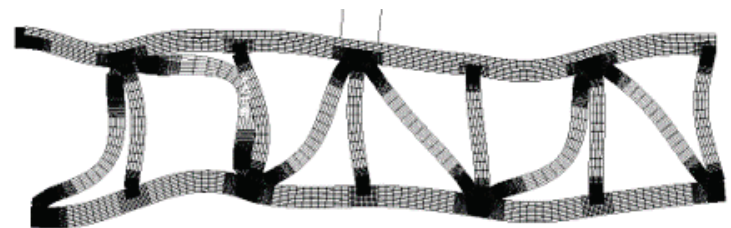

Num. 6: $67.7 \mathrm{~Hz}(+10 \%)$ and $\mathrm{MAC}_{4,6}=0.88$

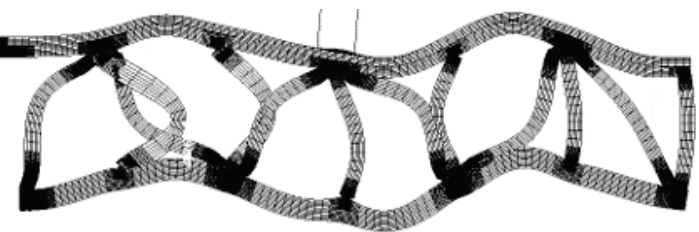

Num. 16: $103 \mathrm{~Hz}(+11 \%)$ and $\mathrm{MAC}_{5,16}=0.9$

Table 2: Experimental and numerical eigenmodes and their MAC values.

\section{CONCLUSIONS}

There is still limited knowledge on the stiffness and damping of real timber connections for dynamic loads. This study, comparing modal data measured on a real large structure and modal data from a detailed 3D FE-model, shows the suitability of modal analysis methods. Non-linear embedment stiffness between timber and the dowels is likely to be important and further studies on damping properties in timber structures must be performed to better evaluate the dissipation of energy. The FE-model presented in this article will be further developed and reduced in coming investigations.

\section{ACKNOWLEDGEMENT}

We would like to express our thanks to Moelven Töreboda AB for the opportunity and the help to measure in their factory while manufacturing had to run with a tight schedule for the building project. The authors gratefully acknowledge the funding for the project "Tall Timber Buildings - concept studies" from Formas the Swedish Research Council for Environment, Agricultural Science and Spatial Planning [Dnr: 942-2015-115].

\section{REFERENCES}

[1] Kjell Arne Malo, Rune B Abrahamsen, and Magnus A Bjertnaes. Some structural design issues of the 14-storey timber framed building "Treet" in Norway. European Journal of Wood and Wood Products, 74(3):407-424, 2016.

[2] Marie Johansson, Andreas Linderholt, Kirsi Jarnerö, and Pierre Landel. Tall timber buildings - a preliminary study of wind-induced vibrations of a 22-storey building. In WCTE World Conference on Timber Engineering, 2016. 
[3] Thomas Reynolds, Daniele Casagrande, and Roberto Tomasi. Comparison of multi-storey cross-laminated timber and timber frame buildings by in situ modal analysis. Construction and Building Materials, 102:1009-1017, 2016.

[4] Angela Feldmann, Huang Haoyu, Wen-Shao Chang, Richard Harris, Philipp Dietsch, Martin Gräfe, and Carsten Hein. Dynamic properties of tall timber structures under windinduced vibration. In WCTE 2016, World Conference on Timber Engineering, 2016.

[5] Samuel Cuerrier Auclair, Lin Hu, Sylvain Gagnon, and Mohammad Mohammad. Effect of type of lateral load resisting system on the natural frequencies of mid- to high-rise wood buildings. In WCTE 2018, World Conference on Timber Engineering, 2018.

[6] Rune Abrahamsen et al. Dynamic response of tall timber buildings under service load the DYNATTB research program. In EURODYN 2020, XI International Conference on Structural Dynamics, 2020.

[7] CEN. Eurocode 5: Design of timber structures - part 1-1: General - common rules and rules for buildings. European Standard EN 1995-1-1, Comité Européen de Normalisation, 2004.

[8] SIA. Timber structures. Swiss Standard SIA 265, Swiss Society of Engineers and Architects, 2012.

[9] Robert Jockwer and André Jorissen. Load-deformation behaviour and stiffness of lateral connections with multiple dowel type fasteners. In INTER 2018, International Network on Timber Engineering Research, 2018.

[10] Patrick Racher and Jean-François Bocquet. Non-linear analysis of dowelled timber connections: a new approach for embedding modelling. Electronic Journal of Structural Engineering, 5, 2005.

[11] Romain Lemaître, Jean-François Bocquet, Michael Schweigler, and Thomas Bader. Beam-on-foundation modelling as an alternative design method for timber joints with dowel-type fasteners-part 2: Modelling techniques for multiple fastener connections. In INTER 2019, International Network on Timber Engineering Research, 2019.

[12] Michael Schweigler, Thomas Bader, Jean-François Bocquet, Romain Lemaittre, and Carmen Sandhaas. Embedment test analysis and data in the context of phenomenological modeling for dowelled timber joint design. In INTER 2019, International Network on Timber Engineering Research, 2019.

[13] Bo-Han Xu, Mustapha Taazount, Abdelhamid Bouchaïr, and Patrick Racher. Numerical 3d finite element modelling and experimental tests for dowel-type timber joints. Construction and Building Materials, 23:3043-3052, 2009.

[14] Luis F. Sirumbal-Zapata, Christian Málaga-Chuquitaype, and Ahmed Y. Elghazouli. A three-dimensional plasticity-damage constitutive model for timber under cyclic loads. Computers Structures, 195:47-63, 2018.

[15] Carmen Sandhaas, Ani Khaloian Sarnaghi, and Jan-Willem van de Kuilen. Numerical modelling of timber and timber joints: computational aspects. Wood Science and Technology, 54:31-61, 2020. 
[16] Mislav Stepinac, Iztok Šušteršič, Igor Gavrić, and Vlatka Rajčić. Seismic design of timber buildings: Highlighted challenges and future trends. Applied Sciences 10, 4:1380, 2020.

[17] Nathalie Labonnote, Anders Rønnquist, and Kjell Arne Malo. Prediction of material damping in timber floors, and subsequent evaluation of structural damping. Materials and Structures 48, 6:1965-1975, 2015.

[18] CEN. Eurocode 5: Design of timber structures - part 2: Bridges. European Standard EN 1995-2, Comité Européen de Normalisation, 2004.

[19] CEN. Timber structures - glued laminated timber and glued solid timber - requirements. European Standard EN 14080, Comité Européen de Normalisation, 2013.

[20] Pierre Landel, Andreas Linderholt, and Johansson. Marie. Dynamical properties of a large glulam truss for a tall timber building. In WCTE 2018, World Conference on Timber Engineering, 2018.

[21] Hans Joachim Blaß and Ireneusz Bejtka. Numerische Berechnung der Tragfähigkeit und der Steifigkeit von querzugverstärkten Verbindungen mit stiftförmigen Verbindungsmitteln (in german). Technical report, Karlsruher Institut für Technologie (KIT), 2008.

[22] Sven Thelandersson and Hans J. Larsen. Timber engineering. John Wiley Sons, 2003. 